\title{
PATHOGEN, HOST CELL RESPONSE, DIAGNOSIS AND THERAPY OF BRUCELLOSIS
}

Jian Wang

Faculty of Veterinary Medicine, Southwest University, Chongqing 40070o, China

*Corresponding author: janeo931@126.com

\section{INTRODUCTION}

Brucellosis is one of the most ubiquitous zoonosis with global distribution (Gul et al. 2015; Massis et al. 2019). Etiology of this disease is Brucella that is a facultative intracellular pathogen. In Brucella genus, 11 species are recognized (Gul et al. 2013; Mesureur et al. 2018). The disease may affect bovine, caprine, ovine, swine, and humans. Due to lack of hygienic processes, public health measures, even national animal health managing policies, the disease is more common in developing countries (Thakur et al. 2002; Farouk et al. 2017; Hasan et al. 2021). Brucellosis causes abortion, reduced fertility, decreased milk production and cost of replacement (Khan and Zahoor 2018). Serious socioeconomic issues can be posed by the disease to livestock owners (Khan et al. 2020). Due to rapidly increasing intercontinental tourism and animal trade, there are high chances that the disease could spread in developed countries (Imtiaz et al. 2018). Brucellosis in humans frequently results in a typical undulant fever, with osteoarthritis as usual impediments (López-Santiago et al. 2019). The intracellular biology of the Brucella is the consequence of complicated interfaces with host that is mandatory to determine a role of pathogen existence and multiplication. In spite of the risk to the public health, there are no effective vaccines to counteract many of them. In this chapter, advances in the field of the pathogen, host cell response, diagnosis and therapy of brucellosis are described.

\section{History, Spread and Pathogen}

Huge economic losses are rendered by the Brucellosis (Shahzad et al. 2018), especially in food animal production sector. The economic losses in animals due to Brucellosis are primarily due to abortions, occurring during the last trimester, decreased milk yield, transient infertility and perinatal mortalities (Gul et al. 2015; Zeng et al. 2019; Khan et al. 2020). The disease is endemic in the buffalo and cattle, causing approximate economic loss of US \$ 344 billion to the animal industry ( $\mathrm{Pal}$ et al. 2020). In some countries of the world, animal Brucellosis has been eradicated, but in many other countries it remained uncontrolled (Gomez et al. 2013). Due to its zoonotic aspect, high incidence in humans has been reported from different countries (Wang and Jiang 2020), including Yemen (89.96\%), Kenya (203.07 cases per 100 ooo), Syria (47.26\%), Greece (42.96\%) and Eritrea (21.82\%). However, this disease continues to exist, particularly in Africa, India, South and Central America, Middle East and the
Mediterranean region (Baldane et al. 2012; Wang and Jiang 2020; Akya et al. 2020). In the past, in humans, 0.5 million new cases have been reported due to Brucellosis annually (Franco et al. 2007; Pal et al. 2020). On the basis of published reports about Brucellosis, Iran stands second in the world with an annual prevalence of 98-130 people/10o,ooo populations (Marvi et al. 2018).

It is documented that David Bruce from Royal British Medical Staff examined it as "Malta fever" or "Mediterranean fever", while the British troops were enduring high fever for long time. David Bruce was able to culture the bacterium liable for the disease in 1887 . Afterwards, Themistocles Zammit's discovered that people rearing goats, and drinking their milk also exhibited similar signs, as those of Mediterranean fever patients. Then, Zammit was able to reproduce the disease in healthy goats, who also isolated Brucella from milk and blood. He concluded that the personals of British Army could have caught the disease by drinking milk from contaminated goats (López-Santiago et al. 2019). Based on these results, though, a decision to ban goat's milk consumption in the British army was made in 1906, however, Malta fever was not eradicated but doubts evolved regarding the use of cheese, and ice-cream made from contaminated milk. Findings of Zammit demonstrated that Brucellosis is commonly transmitted via oral route. Later, other routes were documented (parenteral, respiratory, or by contact) and the disease was believed to be the occupational hazard (Mantur et al. 2007; Gomez et al. 2013; Gul et al. 2015; Shahzad et al. 2017). It has been reported that following possible risk factors can be responsible for human brucellosis: i) eating contaminated animal products, ii) occupational exposure, and iii) contact with diseased animals or their products and/or discharges (Pal et al. 2020).

Classification of Brucella spp. is established on host inclination and virulence (Cloeckaert et al. 2002). The genus Brucella consists of seven species based on primary host and antigenic variation: Brucella abortus (cattle), $B$. melitensis (sheep and goats), B. ovis (sheep), B. canis (dogs), B. neotomae (wood rats), and B. suis (hogs). Brucella abortus causes abortion spontaneously in bovines, thus leading to major monetary losses to livestock farmers. Currently, B. melitensis REV.1 or B. abortus $\mathrm{RB}_{51}$ strains are being utilized to vaccinate caprine and ovine or bovine, respectively (Atluri et al. 2011; Shahzad et al. 2018; Dadar et al. 2019; Celli 2019). Causative agent of Brucellosis can survive for two to four months under natural environment but would die in 1020 minutes at $60^{\circ} \mathrm{C}$, by disinfectants of peroxides, iodine 
or chorine. Bacteria of Brucellosis form intracellular phagocytotic vesicles to escape from the effects of antibiotics (Ugalde et al. 200o). The membranes are made of cellulose, peripheral cytoplasm membrane and the outer membrane, with outside enveloped cytoderm and peptidoglycan; it has well known antigen involved phosphatide, lipopolysaccharide and proteins distributed at out membrane. For example, different peptides have been reported, such as $10 \mathrm{ku} / \mathrm{kd}, 16.5 \mathrm{ku} / \mathrm{kd}, 19 \mathrm{ku} / \mathrm{kd}, 25-$ $34 \mathrm{ku} / \mathrm{kd}, 31-38 \mathrm{ku} / \mathrm{kd}$ and $89 \mathrm{ku} / \mathrm{kd}$, especially genes of omp25 and omp31 ecode 25-34 ku/kd proteins (Fig. 1).

Lipopolysaccharide of Brucella strains are in both smooth and rough forms (Corbel 1990). The rough strains, comprising no or low $\mathrm{O}$ polysaccharide (OPS), usually are less potent than smooth strains and are also less challenging to complement strike (Ko and Splitter 2003). However, sometimes spontaneously virulent strains, like $B$. canis and B. ovis, are rough stains. Virulence factor can be identified by two aspects of Brucella LPS. First, less immunogenic LPS amount in the Brucella than enterobacterial LPS. Whereas, non-pyrogenic Brucella LPS are unable to stimulate the alternate perfect route to a substantial level and is a very mild mitogen B cells (Sangari and Aguero 1996). Furthermore, 10 times more Brucella LPS is needed for interferon (IFN) production and lethality compared to bacterial endotoxins (Keleti et al. 1974; Ko and Splitter 2003). Thus, Brucella LPS low biological activity is necessary for the survival of Brucella in phagocytic cells (McQuiston et al. 1999). Second, OPSdeficient Brucella mutations are vulnerable to complement-mediated lysis and polymyxin $\mathrm{B}$, as in vivo and in vitro $B$. abortus phosphomannomutase (pmm) transposon mutants were attenuated (Allen et al. 1998; Ko and Splitter 2003) and were susceptible to complementmediated killing.

Brucella infection begins via ingestion or inhalation of the causative organisms through the oral, nasal, and pharyngeal cavities (Morgan and Corbel 1990). Following their entry into the mucosal epithelium, the bacteria are carried out to the regional lymph nodes, either in free form or within phagocytic cells. The propagation and proliferation of Brucella in liver, spleen, lymph nodes, mammary glands, bone marrow, and sex organs takes place through macrophages (Godfroid et al. 1998). In general, humans get $B$. abortus, $B$. melitensis, and $B$. suis infections and usual pathological manifestations include endocarditis, arthritis, spondylitis, meningitis etc. (Ko and Splitter 2003).

\section{Pathophysiology}

Brucella enters into the animal body via oral cavity; it comes-across several hurdles, like saliva that is rich source of antibodies, neutrophils, plasma cells, complement molecules, etc. After passing through the mucosal barriers of digestive system, the pathogen is defensed by the intestinal mucosa, containing proteins as well as immune cells (Mowat and Agace 2014) involved T lymphocyte and B lymphocyte in gut associated lymphoid tissue (GALT), such as mesenteric lymph nodes (MLN) and Peyer's patches (Forchielli and Walker 2005). Mucosal cells along with phagocytic cells in these tissues recognize Brucella pathogens. Dendritic cells (phagocytic cells) and macrophages (antigen-presenting cells, APCs) are capable to engulf Brucella and take them to the nearby local lymph node (López-Santiago et al. 2019). As soon as these cells engulf Brucella, APCs move to the lymph node to introduce the bacteria to the lymphocytes and then deliver it to the proper activation signal.

\section{Host cell response to antigen}

\section{Innate immune responses}

Brucella spp. infect phagocytizing cells and disrupt intracellular trafficking pathways. It allows antigen to invade defensive processes to induce an intracellular environment which is favourable for existence and multiplication of the antigen and to provide a means for propagation. After breaking the mucosal obstacles, Brucella affects intraepithelial phagocytic or submucosal cells and sabotage intracellular operating pathways (Pappas et al. 2005; Gomez et al. 2013). This pathway permits Brucella spp. to invade defensive mechanisms of host phagocytosis to create an intracellular environment that could play a role for the survival and duplication of pathogen and to support distribution of host cells (Adams 2002). The most important virulence factor of Brucella spp. is its capability of existence and multiplication within the phagocytic cells, in addition to the processes which lead to death of cells at intracellular level. Brucella spp. can affect various cells, such as epithelial cells, monocytes, macrophages, B lymphocytes, DC, etc. The antigen is depicted by macrophages, where it is recognized as intracellular processes, i.e., phagosomelysosome fusion (Pizarro-Cerda et al. 1998) and respiratory burst via components, such as LPS and those of the type-IV secretion system (Franco et al. 2007). The Brucella spp. are intercellular bacteria, which favors their survival and tenacity by dogging the host immune system (Skendros et al. 2011; Gomez et al. 2013).

\section{Adaptive immune responses}

Adaptive immune reactions are essential for aiding the memory purposes in vaccination. In Brucellosis, purposes of the adaptive immune response can be classified into three mechanisms: i) $\gamma \delta \mathrm{T}, \mathrm{CD}_{4}+$ and CD8+ produce IFN$\gamma$ by triggering macrophages against the bactericidal activities to obstruct the survival of the Brucella intracellularly; ii) cytotoxicity of $\gamma \delta \mathrm{T}$ and CD8+ cells kill the macrophages infected with the Brucella (Bessoles et al. 2011; Zheng et al. 2018); iii) Th1-type antibody isotypes, such as IgG2a and $\operatorname{IgG}_{3}$, opsonize the pathogen to enable phagocytosis (Ghaderinia and Shapouri 2017). The key role of $\mathrm{T}$ cells in Brucella immunity is the excretion of IFN- $\gamma$ for the stimulation of cytotoxic T-lymphocyte activity and bactericidal activity in the macrophages. The importance of $\mathrm{CD}_{4}+\mathrm{T}$ and/or $\mathrm{CD} 8+\mathrm{T}$ cells in Brucella immunity has been presented as histocompatibility complex (MHC) class I and II (Fig. 2). 


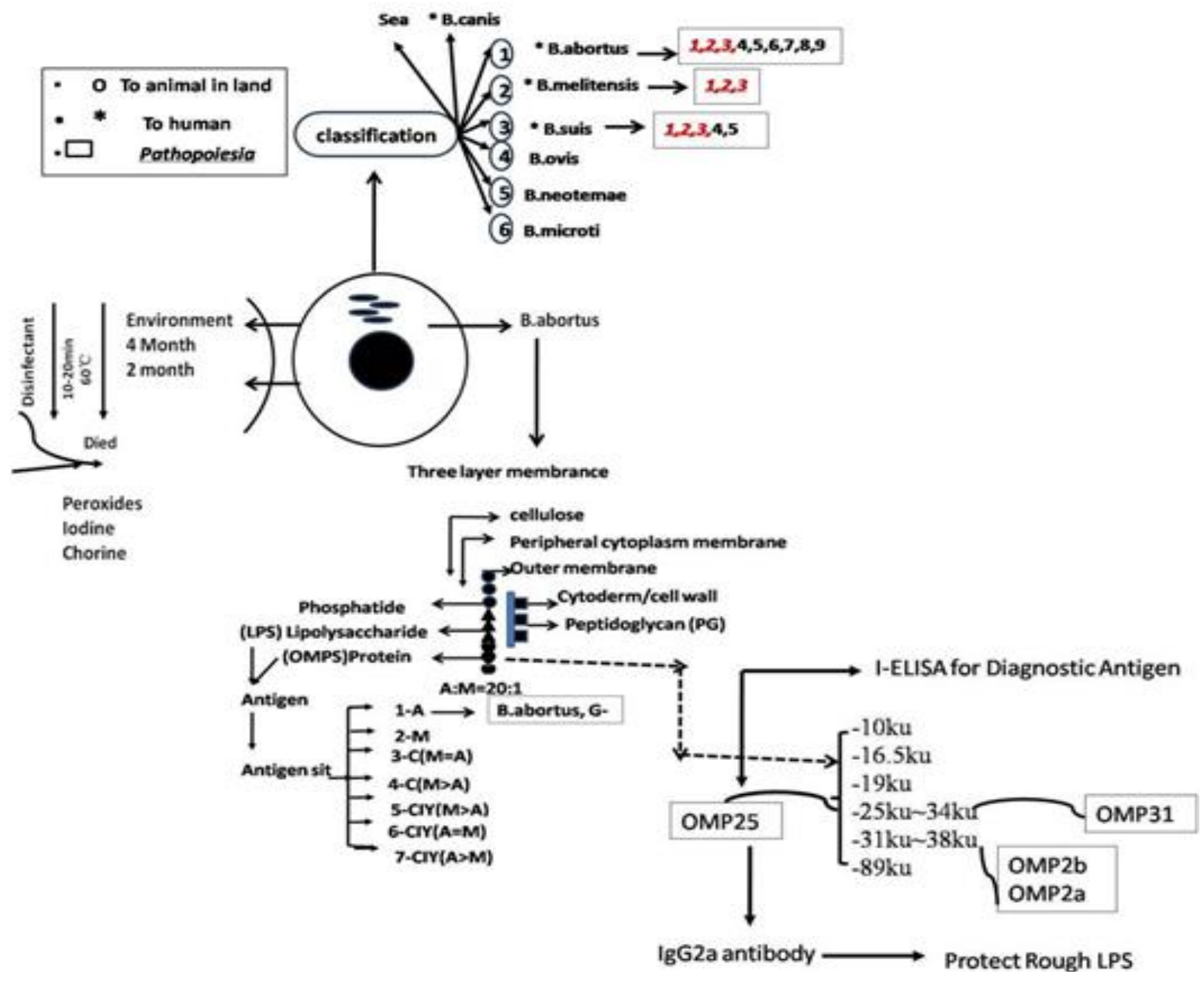

Figure 1: Pathogenesis of Brucellosis in the body.

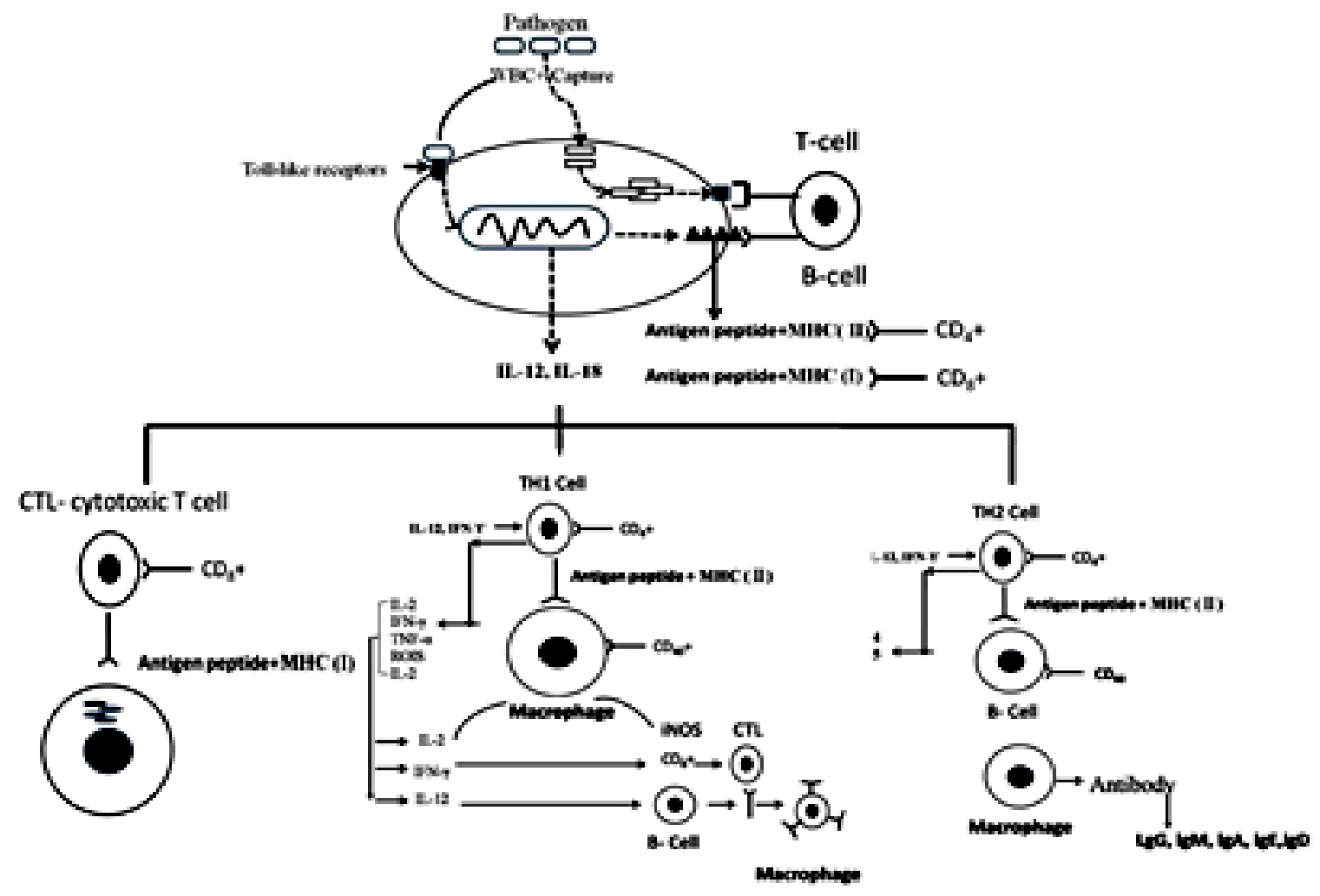

Figure 2: Mechanism of presented histocompatibility complexes. 
Macrophages and T-cells play a vital role in the defense. The helper T-cell-arbitrated defense is mainly linked with a Th1 T-cell reaction and perseverance with a Th2 response (Yingst and Hoover 2003; Perkins et al. 2010; Skendros et al. 2011; Gomez et al. 2013). Precisely, results have indicated defensive aids for TNF- $\alpha$, IFN- $\gamma$, and IL-12 against Brucellosis (Murphy et al. 2001; Brandao et al. 2012). Cytotoxicity of $\mathrm{T}$ cells and $\mathrm{T}$-cell derived cytokinemediated orchestration of the immune response in defense against the Brucellosis is important (Araya et al. 1989; Huy et al. 2021). Role of dendritic cells in adaptive and innate immunity and their survival at the level of mucosal surfaces renders them important in the study of the Brucellosis (Iwasaki 2007). The dendritic cells have been shown to be permeable to brucellae multiplication and infection (Bosio and Dow 2005). Brucella has been proved to control the reaction of these cells, i.e., dendritic cells (Iwasaki 2007; Imtiaz et al. 2018). Lastly, natural killer cells are cells with cytotoxic abilities and have ability to produce IFN, but a title role for these cells in the control of acute Brucellosis is not clear (Vivier et al. 2011; Gomez et al. 2013).

\section{Humoral immunity}

Accurate defensive processes of humoral immunity against intracellular pathogens, like Brucella, lacking in $\beta$ cell activity specify that this cell type is not essential for the defense at the level of primary infection, yet antibodies from the vaccinated and immunized or exposed animals provide necessary defense to the animals not exposed to the disease (Goenka et al. 2011). Moreover, results of a previous study indicate that antibodies possess a protecting role compared to re-infection with Brucella spp. (Gomez et al. 2013). The results further indicate that the innate immunity mechanisms, that herald expansion of humoral immunity, are adequate to overcome the primary Brucella infection and the synergetic and/or repressive impacts of antibodies need to be studied (Titball 2008).

\section{Diagnosis}

Clinically, the disease in animals often characterized by clinical signs, such as abortion, retained placenta, arthritis, orchitis, and epididymitis with excretion of the Brucella spp. in discharges and milk (Shahzad et al. 2017). There are different methods for diagnosis of Brucellosis, but the gold standard test remains the culture isolation (Ko and Splitter 2003; Gul et al. 2015). Serum agglutination tests and milk ring test are being used for the screening of the patient. Important isolation sources are milk and vaginal discharge from infected animals. Moreover, when there is abortion, then organs of aborted fetus, including stomach content, lymph nodes, etc. are the best sources for isolation of the bacteria (Singh et al. 2014). Phage typing, a very handy tool for species and biovars characterization along with biochemical tests, has been in use (Singh et al. 2014). Additionally, different serological tests involving $\operatorname{lgM}$ isotype, $\operatorname{lgG} 1$ and $\lg$ A have also been reported (Weynants et al. 1996).

With advancements in the field of diagnosis, many laboratory tests, such as 16s rRNA, ELISA and PCR across the world are in use; these tests help in the development of molecular markers which are specific and sensitive assays for the detection of Brucella spp. (Shahzad et al. 2017; Imtiaz et al. 2018). PCR-based methods that point out the molecular markers are more helpful and practical in nature than other assays and may take sometime to be fully functional and applicable in the field. PCR-based methods are quick, simple, possess high sensitivity and less hazardous (Singh et al. 2013) for Brucella detection, especially those using the $16 \mathrm{~S}$ rRNA as targets (Shahzad et al. 2018) and the bcsp31 genes (Singh et al. 2014; Imtiaz et al. 2018) are highly sensitive for genus Brucella.

\section{Therapy}

Brucellosis is usually treated with antibiotics, like rifampin, streptomycin, gentamicin and doxycycline. However, the effect of treatment is usually limited. So, vaccine development is the best way for treatment, prevention and control of Brucellosis.

In human Brucellosis, most commonly implicated agents are B. abortus, B. melitensis, and B. suis (Franco et al., 2007; Wattam et al. 2009; Gomez et al. 2013). The virulence of these organisms is variable, with $B$. melitensis being at the top. Vaccination is the most effective and low-cost solution for the prevention of the disease (Oyewumi et al. 2010; Imtiaz et al. 2018). There are two main procedures to produce immune-protection against Brucellosis, vaccination of the animals/humans with liveattenuated organisms or subunit antigens (Gomez et al. 2013). However, the success of this type of immunization approach is influenced by multiple factors, including pathogen biology, efficacy, safety, and adequate levels of immunization.

The first vaccine used in cattle to control Brucellosis was the S19 vaccine (Imtiaz et al. 2018). This vaccine is a live attenuated when administered via action of cytotoxic-Tlymphocytes it produced protective immunity (Levitz and Golenbock 2012), however, it is very difficult to differentiate between infected and vaccinated animals, as both types of animals show a similar serological response (Al-Dahouk et al. 2005). Another vaccine, RB51, was unstable (Moriyon et al. 2004). Presently, live attenuated Brucella vaccines are being used to control the disease in animals, however, major difficulty of their wide application is about human's safety against them (Ficht et al. 2009; Goodwin Pascual 2016; Zhang et al. 2017; Lalsiamthara and Lee 2017).

Brucella melitensis Rev.1 is also a live attenuated vaccine, commonly used in animals for the control of Brucellosis (Levitz and Golenbock 2012; Avila-Calderon et al. 2013). The presence of smooth LPS in the vaccinal strain Rev-1 might make it difficult to differentiate between infected and vaccinated individuals, and may also interfere in the test-and-slaughter policy (Khan et al. 2017). Disadvantages of live attenuated vaccines are that, being 
pathogen for humans and animals, they may i) lead to the development of resistant to streptomycin, ii) could cause abortion in pregnant animals, and iii) produce specific antibodies against LPS that may impede diagnosis (Gwida et al. 2010; Khan et al. 2017; Imtiaz et al. 2018).

It has been documented that subunit vaccines are safe and efficient against $B$. abortus in both humans and animals (Dorneles et al. 2015). Various subunit (Ghasemi et al. 2015), DNA (Leclercq et al. 2003; Al-Mariri et al. 2010) or live vector vaccines have been produced (Cabrera et al. 2009). Humoral, as well as cellular, immunity both play a significant role in protective immunity against Brucella infection, though cell-mediated immunity is likely to perform an important role in the safety, as Brucella is a pathogen that is present intracellularly (Gul et al. 2015). The IFN- $\gamma$ is secrete by the $C_{4}+$ and CD8+ T lymphocytes, and is reported to play an important role in the control of Brucellosis (He et al. 2002). When DNA vaccine is used to immunize animals, both humoral, as well as cellular, immunity is produced against many pathogens (Villinger et al. 2004; Donnelly et al. 2005), thus, the effectiveness of DNA vaccine against $B$. abortus is augmented by encoding various genes, like SOD, L7/L12, and BCSP31 (Da-Hai et al. 2007; Imtiaz et al. 2018). Similarly, recombinant flagellar proteins (FlgJ and FliN) and DNA vaccine encoding BAB1_0270, BAB1_0278, BAB1_0278a (Sislema-Egas et al. 2012; Li et al. 2016) were used to produce a good immune retort and safety against B. abortus infectivity (Escalona et al. 2017).

\section{REFERENCES}

Adams LG, 2002. The pathology of Brucellosis reflects the outcome of the battle between the host genome and the Brucella genome. Veterinary Microbiology 90: $553-561$.

Akya A et al., 2020. Usefulness of blood parameters for preliminary diagnosis of Brucellosis. Journal of Blood Medicine 11: 107-113.

Al-Dahouk S et al., 2005. Identification of Brucella species and biotypes using polymerase chain reactionrestriction fragment length polymorphism (PCRRFLP). Critical Reviews in Microbiology 31: 191-196.

Allen CA et al., 1998. Transposon-derived Brucella abortus rough mutants are attenuated and exhibit reduced intracellular survival. Infection and Immunology 66: 1008-1016.

Al-Mariri A et al., 2001. Protection of BALB/c mice against Brucella abortus 544 challenge by vaccination with bacterioferritin or $\mathrm{P}_{39}$ recombinant proteins with CpG oligodeoxynucleotides as adjuvant. Infection and Immunity 69: 4816-4822.

Araya LN et al., 1989. Temporal development of protective cell mediated and humoral immunity in BALB/c mice infected with Brucella abortus. Journal of Immunology 143: 3330-3337.

Atluri VL et al., 2011. Interactions of the human pathogenic Brucella species with their hosts. Annual Reviews in Microbiology 65: 523-541.
Avila-Calderon ED et al., 2013. A history of the development of Brucella vaccines. BioMed Research International 20: 743509.

Baldane S et al., 2012. An atypical presentation of Brucellosis in a patient with isolated thrombocytopenia complicated with upper gastrointestinal tract bleeding. Case Reports in Medicine 2012: 473784 .

Bessoles S et al., 2011. Role of $\mathrm{NKG}_{2} \mathrm{D}$ and its ligands in the anti-infectious activity of VgammagVdelta2 $\mathrm{T}$ cells against intracellular bacteria. European Journal of Immunology 41: 1619-1628.

Bosio CM and Dow SW, 2005. Francisella tularensis induces aberrant activation of pulmonary dendritic cells. Journal of Immunology 175: 6792-6801.

Brandao AP et al., 2012. Host susceptibility to Brucella abortus infection is more pronounced in IFN-gamma knockout than IL-12/beta2-microglobulin double deficient mice. Clinical Development in Immunology 2012: 589494 .

Cabrera A et al., 2009. Vaccination with recombinant Semliki Forest virus particles expressing translation initiation factor 3 of Brucella abortus induces protective immunity in BALB/c mice. Immunobiology 214: 467-474.

Celli J, 2019. The intracellular life cycle of Brucella spp. Chapter 7. In: Bacteria and Intracellularity (Cossart P, et al. eds). Wiley Online Library.

Cloeckaert A et al., 2002. Major outer membrane proteins of Brucella spp: Past, present and future. Veterinary Microbiology 90: 229-247.

Corbel MJ, 1990. Brucella. In: Parker MT and Collier LH (ed), Topley and Wilson's Principles of Bacteriology, Virology and Immunology, 8th Ed. Edward Arnold, London, UK, pp: 339-353.

Dadar M et al., 2019. Human Brucellosis caused by raw dairy products: A review on the occurrence, major risk factors and prevention. International Journal of Food Microbiology 292: 39-47.

Da-Hai YU et al., 2007. A combined DNA vaccine encoding $\mathrm{BCSP}_{31}, \mathrm{SOD}$, and $\mathrm{L}_{7} / \mathrm{L} 12$ confers high protection against Brucella abortus 2308 by inducing specific CTL responses. DNA Cell Biology 26: 435-443.

Donnelly JJ et al., 2005. DNA vaccines progress and challenges. Journal of Immunology 175: 633-639.

Dorneles EMS et al., 2015. Recent advances in Brucella abortus vaccines. Veterinary Research 46: 76 .

Escalona $\mathrm{E}$ et al., 2017. Immunogenicity of a multiepitope DNA vaccine encoding epitopes from $\mathrm{Cu}-\mathrm{Zn}$ superoxide dismutase and open reading frames of Brucella abortus in mice. Frontiers in Immunology 8: 125.

Farouk UM et al., 2017. Preliminary study on Brucellosis in cattle in Jigawa state Nigeria. Proceedings of the 54th Annual Congress of the Nigerian Veterinary Medical Association, Printed by University Press Limited Zaria, Kaduna State, Nigeria, pp: 66-71.

Ficht TA et al., 2009. Brucellosis: The case for live, attenuated vaccines. Vaccine 27: $\mathrm{D}_{40}-\mathrm{D} 43$. 
Forchielli $\mathrm{M}$ and Walker $\mathrm{W}$, 2005. The role of gutassociated lymphoid tissues and mucosal defense. British Journal of Nutrition 93: $\mathrm{S}_{41-\mathrm{S}_{4} 8 .}$

Franco MP et al., 2007. Human Brucellosis. Lancet Infectious Diseases 7: 775-786.

Ghaderinia P and Shapouri R, 2017. Assessment of immunogenicity of alginate microparticle containing Brucella melitensis 16M oligo polysaccharide tetanus toxoid conjugate in mouse. Banat's Journal of Biotechnology 8: 83-92.

Ghasemi A et al., 2015. Simultaneous immunization of mice with Omp31 and TF provides protection against Brucella melitensis infection. Vaccine 33: 5532-5538.

Godfroid F, et al., 1998. Identification of the perosamine synthetase gene of Brucella melitensis $16 \mathrm{M}$ and involvement of lipopolysaccharide $\mathrm{O}$ side chain in Brucella survival in mice and in macrophages. Infection and Immunology 66: 5485-5493.

Goenka R et al., 2011. B cell-deficient mice display markedly enhanced resistance to the intracellular bacterium Brucella abortus. Journal of Infectious Diseases 203: 1136-1146.

Gomez G et al. 2013. Host-Brucella interactions and the Brucella genome as tools for subunit antigen discovery and immunization against Brucellosis. Frontiers in Cellular and Infection Microbiology 3: Article \# 17.

Goodwin ZI and Pascual DW, 2016. Brucellosis vaccines for livestock. Veterinary Immunology and Immunopathology 181: 51-58.

Gul ST et al., 2013. Seroprevalence of Brucellosis and associated hemato-biochemical changes in Pakistani horses. Pakistan Journal of Agricultural Sciences 50: 745-750.

Gul ST et al., 2015. Epidemiology of Brucellosis at different livestock farms in the Punjab, Pakistan. Pakistan Veterinary Journal 35: 309-314.

Gwida M et al., 2010. Brucellosis - regionally emerging zoonotic disease. Croatia Medical Journal 51: 289-295.

Hasan TH et al. 2021. Brucella spp. virulence factors: Review. International Journal of Pharmaceutical Research 13: 470-476.

He Y et al., 2002. Recombinant Ochrobactrum anthropi expressing Brucella abortus $\mathrm{Cu}, \mathrm{Zn}$ superoxide dismutase protects mice against $B$. abortus infection only after switching of immune responses to Thi type. Infection and Immunity 70: 2535-2543.

Huy TXN et al., 2021. Immunization with a combination of four recombinant Brucella abortus proteins Omp16, Omp19, Omp28, and L7/L12 induces T Helper 1 immune response against virulent B. abortus 544 infection in BALB/c mice. Frontiers in Veterinary Science 7: 577026.

Imtiaz $W$ et al., 2018. Evaluation of DNA vaccine encoding $\mathrm{BCSP}_{31}$ surface protein of Brucella abortus for protective immunity. Microbial Pathogenesis 125: 514-520.

Iwasaki A, 2007. Mucosal dendritic cells. Annual Review in Immunology 25: 381-418.
Keleti $G$ et al., 1974. Interferon induction in mice by lipopolysaccharide from Brucella abortus. Infection and Immunology 10: 282-283.

Khan MZ and Zahoor M, 2018. An overview of Brucellosis in cattle and humans, and its serological and molecular diagnosis in control strategies. Tropical Medicine and Infectious Disease 3: 65 .

Khan MZ et al., 2017. Molecular characterization of Brucella abortus and Brucella melitensis in cattle and humans at the North West of Pakistan. Pakistan Veterinary Journal 37: 360-363.

Khan UD et al., 2020. Seroprevalence of Brucellosis in cattle (Bos taurus) kept in peri urban areas of Pakistan. Agrobiological Records 1: 6-10.

Ko J and Splitter GA, 2003. Molecular host-pathogen interaction in Brucellosis: Current understanding and future approaches to vaccine development for mice and humans. Clinical Microbiology Reviews 16: 65-78.

Lalsiamthara J and Lee JH, 2017. Development and trial of vaccines against Brucella. Journal of Veterinary Science 18 (Suppl 1): 281-290.

Leclercq $S$ et al., 2003. Enhanced efficacy of DNA vaccines against an intracellular bacterial pathogen by genetic adjuvants. Current Pharmaceutical and Biotechnology 4: 99-107.

Levitz SM and Golenbock DT, 2012. Beyond empiricism: Informing vaccine development through innate immunity research. Cell 148: 1284-1292.

Li X et al., 2016. Vaccination with recombinant flagellar proteins FlgJ and FliN induce protection against Brucella abortus 544 infection in BALB/c mice. Veterinary Microbiology 161: 137-144.

López-Santiago $\mathrm{R}$ et al., 2019. Immune response to mucosal brucella infection. Frontiers in Immunology 10: 1759 .

Mantur BG et al., 2007. Review of clinical and laboratory features of human Brucellosis. Indian Journal of Medical Microbiology 25: 188-202.

Marvi A et al. 2018. Trend analysis and affecting components of human Brucellosis incidence during 2006 to 2016. Medicine Archives 72: 17-21.

Massis FD et al., 2019. Distribution of Brucella field strains isolated from livestock, wildlife populations, and humans in Italy from 2007 to 2015. PLoS One 14: eo213689.

McQuiston JR et al., 1999. Genetic characterization of a Tn 5-disrupted glycosyltransferase gene homolog in Brucella abortus and its effect on lipopolysaccharide composition and virulence. Infection and Immunology 67: 3830-3835.

Mesureur J et al., 2018. A MALDI-TOF MS database with broad genus coverage for species-level identification of Brucella. PLoS Neglected Tropical Diseases 12: eooo6874.

Morgan BWJ and Corbel MJ, 1990. Brucella infections in man and animals: Contagious equine metritis. In: Parker MT and Collier LH (ed), Topley and Wilson's Principles of Bacteriology, Virology and Immunology, 8th Ed. Edward Arnold, London, UK, pp: 547-570. 
Moriyon I et al., 2004. Rough vaccines in animal Brucellosis, structural and genetic basis and present status. Veterinary Research 35: 1-38.

Mowat AM and Agace WW, 2014. Regional specialization within the intestinal immune system. Nature Review of Immunology 14: 667-685.

Murphy EA et al., 2001. Interferon-gamma is crucial for surviving a Brucella abortus infection in both resistant $\mathrm{C}_{57} \mathrm{BL} / 6$ and susceptible $\mathrm{BALB} / \mathrm{c}$ mice. Immunology 103: 511-518.

Oyewumi et al., 2010. Nano-microparticles as immune adjuvants: Correlating particle sizes and the resultant immune responses. Expert Review Vaccines 9: 1095-1107.

Pal $\mathrm{M}$ et al., 2020. Human and animal Brucellosis: A comprehensive review of biology, pathogenesis, epidemiology, risk factors, clinical signs, laboratory diagnosis, public health significance, economic importance, prevention \& control. American Journal of Infectious Diseases and Microbiology 8: 118-126.

Pappas G et al., 2005. Brucellosis. New England Journal of Medicine 352: 2325-2336.

Perkins SD et al., 2010. Towards a Brucella vaccine for humans. FEMS Microbiology Reviews 34: 379-394.

Pizarro-Cerda J et al., 1998. Virulent Brucella abortus prevents lysosome fusion and is distributed within autophagosome-like compartments. Infection and Immunology 66: 2387-2392.

Sangari FJ and Aguero J, 1996. Molecular basis of Brucella pathogenicity: an update. Microbiologia 12: 207-218.

Shahzad A et al., 2017. Seroprevalence and molecular investigations of Brucellosis in camel of selected regions of Pakistan. Thai Journal of Veterinary Medicine 47: 207-215.

Shahzad A et al., 2018. Patho-morphological evaluation of acute infection of Brucella melitensis in goats. Pakistan Veterinary Journal 38: 341-346.

Singh A et al., 2014. Omp31 gene based molecular detection of $B$. melitensis from serum samples of goats. Indian Journal of Animal Sciences 84: 251-253.

Singh A et al., 2013. 16S rRNA and Omp31 gene based molecular characterization of field strains of $B$. melitensis from aborted foetus of goats in India. The Scientific World Journal 2013: Article \# 160376.

Sislema-Egas F et al., 2012. Evaluation of protective effect of DNA vaccines encoding the BAB1_0263 and
BAB1_0278 open reading frames of Brucella abortus in BALB/c mice. Vaccine 30: 7286-7291.

Skendros $\mathrm{P}$ et al., 2011. Cell-mediated immunity in human Brucellosis. Microbes and Infection 13: 134-142.

Thakur SD et al., 2002. Human Brucellosis; a review of an under diagnosed animal transmitted disease. Journal of Communicable Diseases 34: 287-301.

Titball RW, 2008. Vaccines against intracellular bacterial pathogens. Drug Discovery Today 13: 596-6oo.

Ugalde JE et al., 20oo. Identification and characterization of the Brucella abortus phosphoglucomutase gene: Role of lipopolysaccharide in virulence and intracellular multiplication. Infection and Immunology 68: 5716-5723.

Villinger F et al., 2004. IL-15 is superior to IL-2 in the generation of long-lived antigen specific memory $\mathrm{CD}_{4}$ and CD8 $\mathrm{T}$ cells in rhesus macaques. Vaccine 22: 3510-3521.

Vivier E et al. 2011. Innate or adaptive immunity? The example of natural killer cells. Science 331: 44-49.

Wang XH and Jiang H, 2020. Global prevalence of human Brucellosis. Zhonghua Liu Xing Bing Xue Za Zhi 41: 1717-1722.

Wattam AR et al., 2009. Analysis of ten Brucella genomes reveals evidence for horizontal gene transfer despite a preferred intracellular lifestyle. Journal of Bacteriology 191: 3569-3579.

Weynants V et al., 1996. Infection of cattle with Yersinia enterocolitica 0:9 a cause of the false positive serological reactions in bovine Brucellosis diagnostic tests. Veterinary Microbiology 48: 101-112.

Yingst $\mathrm{S}$ and Hoover DL, 2003. T cell immunity to Brucellosis. Critical Reviews in Microbiology 29: 313331.

Zeng JY et al., 2019. Evaluation of the economic impact of Brucellosis in domestic yaks of Tibet. Transboundary Animal Diseases 66: 476-487.

Zhang JB et al., 2017. The Brucella melitensis M5-9o Delta manB live vaccine candidate is safer than $\mathrm{M}_{5-90}$ and confers protection against wild-type challenge in BALB/c mice. Microbial Pathogenesis 112: 148-155.

Zheng $\mathrm{R}$ et al., 2018. Meta-analysis of the changes of peripheral blood $\mathrm{T}$ cell subsets in patients with Brucellosis. Journal of Immunology Research 2018: Article \# 8439813. 